\title{
Kernos
}

Revue internationale et pluridisciplinaire de religion grecque antique

$25 \mid 2012$

Varia

\section{Andrei TIMOTIN, La démonologie platonicienne. Histoire de la notion de Daimōn de Platon aux derniers néoplatoniciens}

André Motte

\section{OpenEdition}

Journals

Édition électronique

URL : http://journals.openedition.org/kernos/2077

DOI : 10.4000/kernos.2077

ISSN : 2034-7871

Éditeur

Centre international d'étude de la religion grecque antique

Édition imprimée

Date de publication : 26 octobre 2012

Pagination : 373-374

ISSN : 0776-3824

Référence électronique

André Motte, « Andrei TIMOTIN, La démonologie platonicienne. Histoire de la notion de Daimōn de Platon aux derniers néoplatoniciens », Kernos [En ligne], 25 | 2012, mis en ligne le 01 octobre 2012, consulté le 21 septembre 2020. URL : http://journals.openedition.org/kernos/2077 ; DOI : https://doi.org/ 10.4000/kernos.2077

Ce document a été généré automatiquement le 21 septembre 2020

Kernos 


\title{
Andrei TIMOTIN, La démonologie platonicienne. Histoire de la notion de Daimōn de Platon aux derniers néoplatoniciens
}

\author{
André Motte
}

\section{RÉFÉRENCE}

Andrei timotin, La démonologie platonicienne. Histoire de la notion de Daimōn de Platon aux derniers néoplatoniciens, Leiden/Boston, Brill, 2012. 1 vol. 16,5 × 24,5 cm, xi+404 p. (Philosophia Antiqua, 128). ISBN : 978-90-04-21810-9.

Cette version remaniée d'une thèse de doctorat, entreprise à l'EPHE de Paris sous la direction de Philippe Hoffmann et soutenue en 2010, intéressera vivement les historiens de la religion grecque ainsi que les spécialistes de la philosophie antique, daimôn étant une notion aux résonances à la fois religieuses et philosophiques. Ce sujet très complexe, qui n'avait plus donné lieu depuis de nombreuses années à une étude d'ensemble d'une certaine ampleur, est traité ici avec une remarquable maîtrise. Quand on jette un coup d'œil rapide sur la table des matières et qu'on y voit un chapitre consacré à la notion de daimôn dans la littérature grecque jusqu'à Platon, suivi du chapitre de base consacré aux différents figures du daimôn chez ce dernier, l'idée vient à l'esprit qu'il eût suffi d'une petite place faite aux Épicuriens, aux Stoïciens et à quelques autres pour que soit enfin disponible une étude complète sur la démonologie antique. Mais lorsqu'on découvre à la lecture toutes les ramifications que comporte le thème et les redoutables dédales qu'il faut parcourir pour venir à bout de la tradition platonicienne, l'idée est vite abandonnée et on convient que cette thèse à elle seule en représente déjà plusieurs... 
2 Après l'introduction qui comprend notamment un aperçu historiographique et à laquelle font suite les deux chapitres qu'on vient d'évoquer, le parcours compte encore trois chapitres qui tiennent compte bien évidemment de la chronologie, mais à l'intérieur de trois axes thématiques que retient l'A. : la dimension cosmologique de la démonologie, en relation avec la théorie de la providence, la démonologie et la religion dans le monde gréco-romain, le daimôn personnel et sa place dans la philosophie. Dans chacun de ces trois chapitres, on part donc de l'ancienne Académie pour terminer avec les commentaires néoplatoniciens les plus récents. Des conclusions clôturent chaque partie et des conclusions générales couronnent l'étude.

3 Les spécialistes de la religion grecque seront plus particulièrement intéressés par l'avant-dernier chapitre. Il faut toutefois préciser qu'ils n'y trouveront pas une étude des cultes effectivement rendus aux être divins qualifiés de daimones, mais bien des conceptions théologiques qu'ont développées les héritiers de Platon en se fondant sur le célèbre texte du Banquet qui fait du daimôn un être divin intermédiaire grâce auquel toute prière atteint son destinataire et tout rite son accomplissement. L'ancienne Académie généralisa l'assimilation des dieux aux daimones, mais le médio-platonicien Plutarque maintint partiellement la distinction, considérant que seuls sont des daimones les dieux accessibles au pathos, comme ils le sont dans les cultes à mystères. Il propose aussi une exégèse démonologique des oracles et de certains rites. À la différence de Platon, il semble bien donner crédit à l'existence de mauvais daimones, mais la question est controversée. Tant s'en faut d'ailleurs que les conceptions démonologiques de Plutarque aient été exemptes de variations. Chez les néoplatoniciens, très spécialement chez cette autre figure de proue de la problématique des daimones qu'est Jamblique, l'affirmation platonicienne selon laquelle ces êtres divins sont accessibles à la passion est fermement récusée, ce qui n'empêche pas qu'ils conservent un rôle dans la pratique rituelle. Proclus enfin, dans un remarquable effort de synthèse prolonge les enseignements de Plutarque et de Jamblique.

4 L'impressionnante bibliographie, riche de plus de 700 titres, est suivie de trois précieux indices (locorum, rerum et verborum, termes grecs et latins), qui donnent une bonne idée de la richesse et de l'intérêt du sujet traité. La méthode est sûre, s'appuyant constamment sur les textes originaux, la littérature seconde est bien maîtrisée, les développements sont solidement argumentés, l'appareil justificatif est soigné, l'ouvrage est bien écrit, la clarté du style n'étant pas son moindre mérite. Ce n'est pas dire qu'on partage toutes les vues de l'A. et qu'on n'a pas envie quelquefois de croiser le fer avec lui. Mais s'il n'en était pas ainsi, il y aurait lieu de s'inquiéter... Nul doute que cet ouvrage ne soit accueilli avec faveur, ne suscite d'intéressants débats et n'attise le désir de voir bientôt cette étude étendue aux écoles philosophiques qui sont restées jusqu'ici sur le banc. 


\section{AUTEURS}

ANDRÉ MOTTE

Université de Liège 